\title{
PRODUÇÃO DE MILHO PÓS-PASTAGEM COM APLICAÇÃO SUPERFICIAL DE CALCÁRIO E GESSO AGRÍCOLA
}

\author{
Aline Saraiva Viudes, Luanda Torquato Feba, Edemar Moro Carlos, Sérgio Tiritan \\ Universidade do Oeste Paulista - UNOESTE, Agronomia, Presidente Prudente, SP.
}

\begin{abstract}
RESUMO
O presente trabalho foi realizado com o objetivo de avaliar a produção de milho pós-pastagem, considerando a aplicação de diferentes doses de calcário e gesso agrícola na superfície.O delineamento experimental foi em faixas em esquema parcela subdividida, com quatro repetições. Foram avaliados os seguintes componentes de produção, número de plantas por metro, número de fileiras por espiga, número de grãos por fileira, número de grãos por espiga, total de grãos, peso de 100 grãos e produtividade por hectare. Os dados foram submetidos à análise de variância (ANOVA) teste $\mathrm{F}$ e comparação entre médias pelo teste de Tukey a 1 e $5 \%$ de probabilidade. Verificou-se que as dosagens de calcário não diferenciaram na produtividade do milho sozinho, porém,as diferentes dosagens da interação calcário e gesso agrícola apresentaram diferença significativana produtividade. Conclui-se o gesso agrícola aplicado em altas doses $4 \mathrm{tha}^{-1}$ e $8 \mathrm{t} \mathrm{ha}^{-1}$ de forma isolada, promove queda da produtividade, as doses de $2 \mathrm{t} \mathrm{ha}^{-1}$ de calcário e gesso agrícola, foram as que obtiveram melhor resposta na produtividade do milho, ressaltando que deve se estudar por mais anos a reação que ambos terão no solo e nas próximas culturas.

Palavras-chave: solos arenosos, produtividade, plantio direto.

\section{PRODUCTION OF POST-PASTA CORN WITH SURFACE APPLICATION OF CALCARY AND AGRICULTURAL PLASTER}

\begin{abstract}
The present work was carried out with the objective of evaluating post-pasture maize production, considering the application of different doses of limestone and agricultural gypsum on the surface. The experimental design was in strips in a subdivided plot scheme, with four replications. The following production components were evaluated: number of plants per meter, number of rows per spike, number of grains per row, number of grains per spike, total grains, weight of 100 grains and yield per hectare. Data were submitted to analysis of variance (ANOVA) F test and comparison between means by Tukey test at 1 and $5 \%$ probability. It was verified that the limestone dosages did not differentiate in the yield of the corn alone, however, the different dosages of the limestone interaction and agricultural gypsum presented a significant difference in yield. The agricultural gypsum applied in high doses $4 \mathrm{t} \mathrm{ha}^{-1}$ and $8 \mathrm{t} \mathrm{ha}^{-1}$ in an isolated manner, promotes a fall in yield, the doses of $2 \mathrm{t} \mathrm{ha}^{-1}$ of limestone and agricultural gypsum, were the ones that obtained the best response in Corn yield, emphasizing that one must study for more years the reaction that both will have on the soil and in the next cultures.
\end{abstract}

Keywords: sandy soils, yield, no tillage.

\section{INTRODUÇÃO}

Aproximadamente $30 \%$ dos solos, a nível mundial, são considerados solos ácidos, com exceção dos solos polares (FAGERIA \& BALIGAR, 1997). Para obtermos eficiência na correção de solos acidificados são adotadas práticas de calagem para correção dessa acidez promovendo assim 
a elevação do $\mathrm{pH}$, redução de Alumínio e Manganês trocáveis no solo, saturação por bases e teores de cálcio (CAIRES et al., 2004). A acidez no solo se torna um fator limitante na produção agrícola devidoà toxidez do Al e Mge a baixa saturação por bases (COLEMAN \& THOMAS, 1967).No Brasil, cerca de $40 \%$ da produtividade das culturas é reduzida pela metade, apenas em função dos efeitos deletérios da acidez em profundidade, no desenvolvimento das plantas. Isto porque, a deficiência de cálcio e a toxidez de alumínio são as principais limitações químicas para o crescimento do sistema radicular, cujo as consequências se manifestam pelo estresse nutricional e hídrico nas plantas (RITCHEY et al. 1980).

Para aumentar a produtividade agrícola, a calagem e gessagem se tornam fundamentais para esse feito respeitando as dosagens corretas de cada cultivar e asnecessidades do solo, sem haver desperdícios e obtendo lucros com maior produção.

Mediante a isso, o presente trabalho foi realizado com o objetivo de avaliar a produção de milho pós-pastagem, considerando a aplicação de diferentes doses de calcário e gesso agrícola na superfície (falar da interação).

\section{METODOLOGIA}

O experimento foi conduzido na Fazenda Experimental da Unoeste, localizada no município de Presidente Bernardes-SP, em um solo classificado como Argissolo Vermelho distroférrico (EMBRAPA, 2006). Altitude média de 385 metros e relevo suave ondulado. O clima da região, segundo classificação de Köppen, é do tipo Aw, com verão chuvoso e inverno seco.

$O$ delineamento experimental foi em faixas em esquema de parcelas subdivididas (de parcelas subdivididas), com quatro repetições. As parcelas com dimensões de $75 \mathrm{~m}$ de comprimento por 15 metros de largura foram constituídas por quatro doses de calcário $(1,2,4$ e 8 $\mathrm{t} \mathrm{ha}^{-1}$ ). As subparcelas com dimensões de $15 \mathrm{~m}$ de comprimento por 15 metros de largura foram constituídas por cinco doses de gesso agrícola $\left(0,1,2,4\right.$ e 8 t ha $\left.{ }^{-1}\right)$ conforme aTabela 1 . O calcário utilizado foi o dolomítico com 32\% de $\mathrm{CaO}$ e $12 \%$ de $\mathrm{Mg}$ O e PRNT $85 \%$.

TABELA 1. Descrição dos tratamentos nas parcelas e subparcelas.

\begin{tabular}{|c|c|c|c|c|c|c|}
\hline \multirow[t]{2}{*}{ TRATAMENTO } & \multirow{2}{*}{$\frac{\text { Calcário (parcelas) }}{\left(\mathrm{t} \mathrm{ha}^{-1}\right)}$} & \multicolumn{5}{|c|}{ Gesso (subparcelas) } \\
\hline & & & $\left.a^{-1}\right)$ & & & \\
\hline $\mathrm{T} 1$ & 1 & 0 & 1 & 2 & 4 & 8 \\
\hline $\mathrm{T} 2$ & 2 & 0 & 1 & 2 & 4 & 8 \\
\hline T3 & 4 & 0 & 1 & 2 & 4 & 8 \\
\hline T4 & 8 & 0 & 1 & 2 & 4 & 8 \\
\hline
\end{tabular}

A retirada dos animais da pastagem degradada foi realizada em janeiro de 2014. Após a retirada dos animais da área foi realizada a dessecação da pastagem e a análise química do solo.Foram realizadas as amostragens do solo de cada tratamento, após homogeneização retirouse $300 \mathrm{~g}$ para a análise química de fertilidade no laboratório de análises de solos da UNOESTE segundo a metodologia de Raij (2001). Foram determinados os teores dos macronutrientes (N, P, $\mathrm{K}, \mathrm{Ca}, \mathrm{Mg}$, e S) e micronutrientes (Fe, $\mathrm{Mn}, \mathrm{Cu}$ e $\mathrm{Zn}$ ), conforme as tabelas 2 e 3 :

TABELA 2. Analise química do solo antes da implantação do experimento. 


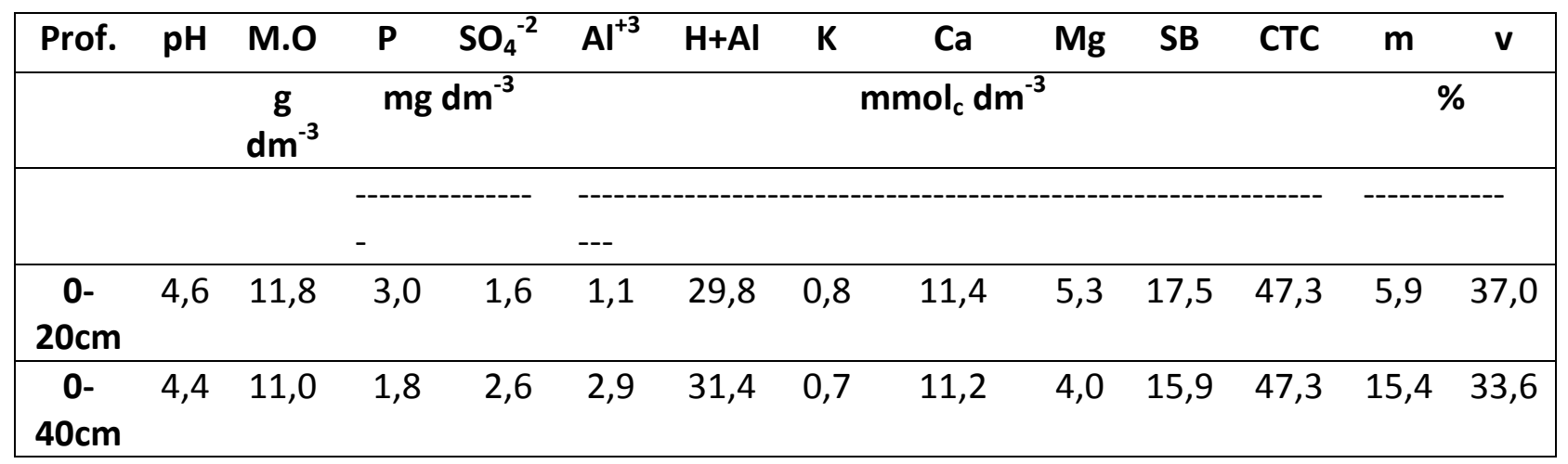

TABELA 3. Analise química de micronutrientes

\begin{tabular}{|c|c|c|c|c|c|c|}
\hline Prof. & Área & Boro & Cobre & Ferro & Manganês & Zinco \\
\hline \multicolumn{7}{|c|}{ mmolc dm-3 } \\
\hline $\begin{array}{c}0- \\
20 \mathrm{~cm}\end{array}$ & & 0,09 & 1,10 & 23,50 & 2,80 & 0,20 \\
\hline $\begin{array}{c}0- \\
40 \mathrm{~cm}\end{array}$ & & 0,08 & 1,00 & 22,60 & 2,20 & 0,10 \\
\hline
\end{tabular}

Após a retirada das análises foram aplicados os tratamentos com as dose de calcário e gesso agrícola, e no final de abril foi semeada aveia preta, para cobertura do solo e rotação de culturas, em seguida no mês de novembro foi feito semeada da soja utilizando o cultivar TMG 1264 RR, esta soja foi colhida em fevereiro de 2015 e realizado o semeado do milho no mês de abril de 2015.0 cultivar de milho híbrido utilizado foi o SYN 7205 TL TG Viptera e tratamento de semente foi realizado, com os agroquímicos VitavaxThiram $200 \mathrm{SC}^{\circledR}$ (Carboxina + Tiran) e Cropstar $^{\circledR}$ (Imidacloprido + Tiodicarbe) nas dosagens recomendada pelos fabricantes. A adubação de semeadura foi com a utilização de $250 \mathrm{~kg} \mathrm{ha}^{-1}$, usando-se a formulação 04-30-10, sendo utilizado o espaçamento de $70 \mathrm{~cm}$ entre linhas, com a deposição de 6 sementes por metro linear. A adubação de cobertura se deu por $60 \mathrm{~kg}$ de $\mathrm{N}$ na forma de ureia.

Para a determinação da produtividade, foram realizadas em 5 metros lineares, retirando três linhas de plantas, com quatro repetições, para a estimativa da produtividade da cultura.

Foram avaliados os seguintes componentes de produção: número de plantas por metro, número de fileiras por espiga, número de grãos por fileira, número de grãos por espiga, total de grãos, peso de 100 grãos e produtividade por hectare. Estes dados foram coletados em laboratório e avaliados através de médias.

Os dados foram submetidos à análise de variância (ANOVA) teste $F$, e comparação entre médias pelo teste de Tukey a 1 e $5 \%$ de probabilidade, utilizando o programa estatístico SISVAR (FERREIRA, 2008).

\section{RESULTADOS}

Nas análises verificou-se que a calagem e a gessagem não influenciaram nos componentes de produção do milho (TABELA 4), isso pode ter ocorrido dado pelo fato do curto período do experimento, resultados já observados em outros trabalhos segundo Silva (1997). Decorridos 24 meses do início do estudo permaneciam praticamente inalterados os efeitos da calagem e da gessagem nas análises superficiais do solo.

Conforme a TABELA 4 pode se observar que a mediada em que as doses de calcário e gesso agrícola aumentaram, não houve diferença estatística no número de plantas por hectare, e em 
nenhum dos componentes de produção do milho, verificando assim que as dosagens de calcário e gesso agrícola não influíram nos componentes de produção do milho, isto pode ter ocorrido a diversos fatores como o pouco tempo de aplicação e a implantação da cultura do milho.

TABELA 4 - Componentes de produção do milho em função de doses de calcário e gesso agrícola.

$\begin{array}{ccccc}\text { NP } & \text { N FILEIRAS/ } & \text { N DE GRÃOS POR } & \text { N DE GRÃOS POR } & \text { TOTAL DE } \\ & \text { ESPIGA } & \text { FILEIRAS } & \text { ESPIGA } & \text { GRÃOS }\end{array}$

Calc.

\begin{tabular}{|c|c|c|c|c|c|}
\hline 1 & 4,1 & 14,4 & 26,5 & 382,6 & 9232,0 \\
\hline 2 & 4,0 & 14,8 & 25,8 & 382,6 & 9316,4 \\
\hline 4 & 4,1 & 14,3 & 25,7 & 365,7 & 8844,8 \\
\hline 8 & 4,3 & 14,5 & 25,6 & 376,9 & 9046,4 \\
\hline $\mathrm{CV}$ & 8,10 & 6,96 & 10,44 & 13,67 & 15,72 \\
\hline \multicolumn{6}{|l|}{ Gess. } \\
\hline 0 & 4,2 & 14,2 & 26,1 & 365,4 & 8878,1 \\
\hline 1 & 4,2 & 14,9 & 26,1 & 391,8 & 9444,0 \\
\hline 2 & 4,0 & 15,6 & 25,6 & 390,9 & 9561,3 \\
\hline 4 & 4,1 & 15,6 & 25,8 & 351,2 & 8430,0 \\
\hline 8 & 4,1 & 14,3 & 25,9 & 384,8 & 9236,0 \\
\hline CV & 7.68 & 12,75 & 8,90 & 14,36 & 13,90 \\
\hline \multicolumn{6}{|c|}{ Probabilidade $(P \geq F)$} \\
\hline Calc. (C) & 0,120 & 0,625 & 0,820 & 0,793 & 0,810 \\
\hline Gess. (G) & 0,381 & 0,113 & 0,983 & 0,289 & 0,202 \\
\hline$C \times G$ & 0,793 & 0,279 & 0,712 & 0,509 & 0,430 \\
\hline
\end{tabular}

*NP=número de plantas por metro

FIGURA 1 Interação das doses de calcário e gesso agrícola em relação à produtividade.

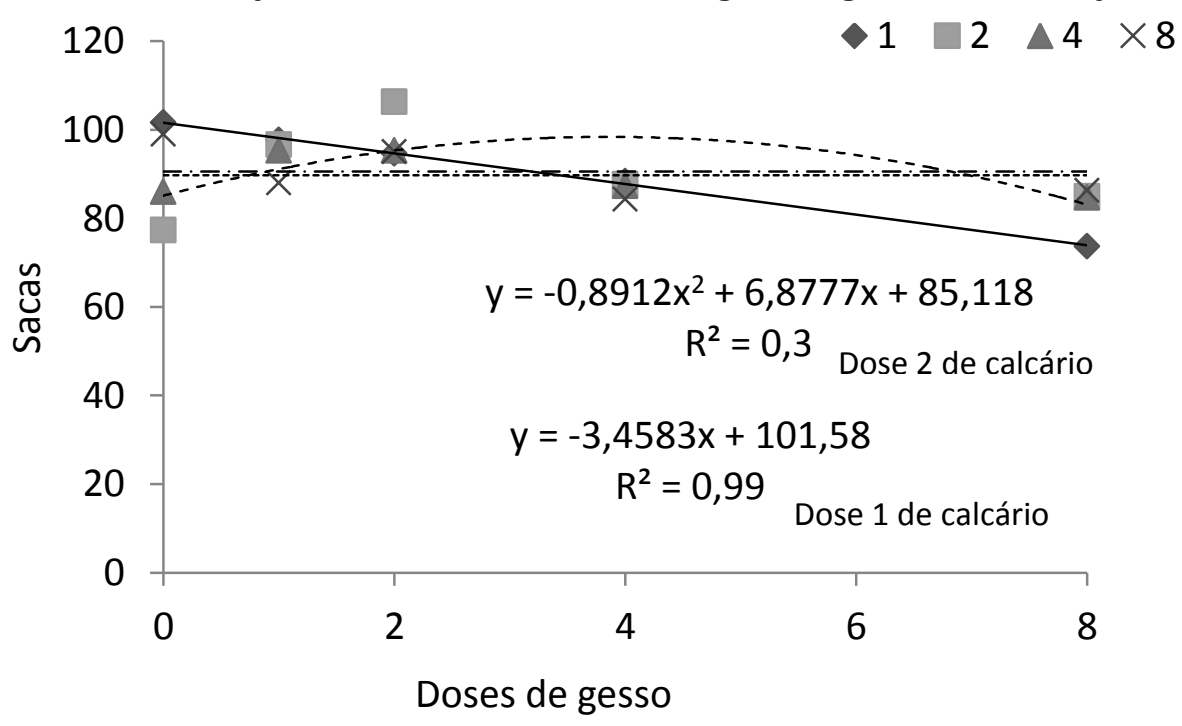

A interação que apresentou melhor resultado nas análises foram a de $2 \mathrm{t} \mathrm{ha}^{-1}$ calcário com $2 \mathrm{t} \mathrm{ha}^{-1}$ de gesso produtividade que chegou a 106 sacas por hectare mostrando que a um incremento da produtividade com as aplicações de calcário e gesso conforme (FIGURA 1),esses 
resultados mostram que a aplicação de gesso em doses elevadas, combinada com o uso de calcário dolomítico, pode causar incrementos importantes na produção de milho, mesmo na ausência de déficit hídrico (CAIRES et al., 2004).

FIGURA 2 Produtividade de grãos em relação a doses de gesso dentro da codificação um de calcário.

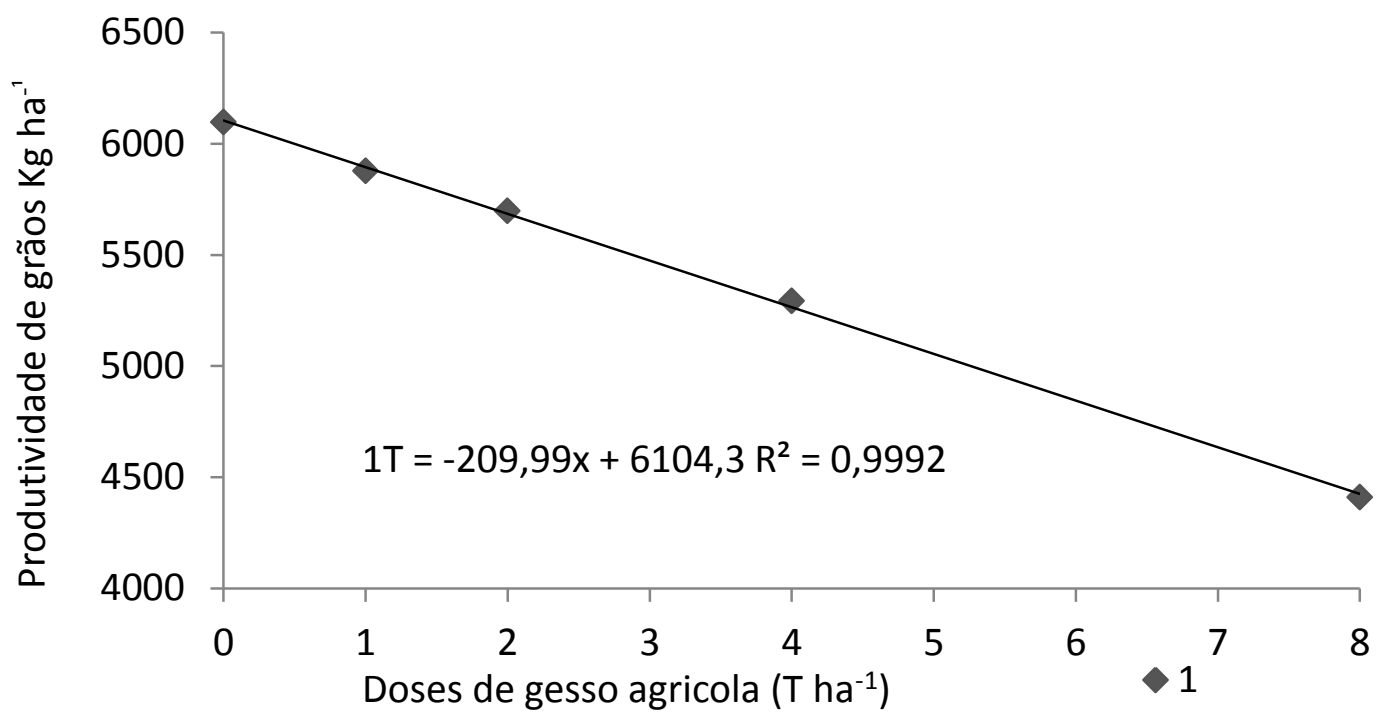

Respostas positivas do milho à aplicação de gesso têm sido observadas em variadas condições de solo e clima (CAIRES et al., 1999).

A FIGURA 3 apresenta uma curva com os dados isolados das doses de gesso agrícola onde mostra que houve um aumento da produtividade até a dose de 2 toneladas por hectare e uma queda da produtividade nas doses seguintes.

FIGURA 3 Produtividade do milho em relação às doses de gesso.

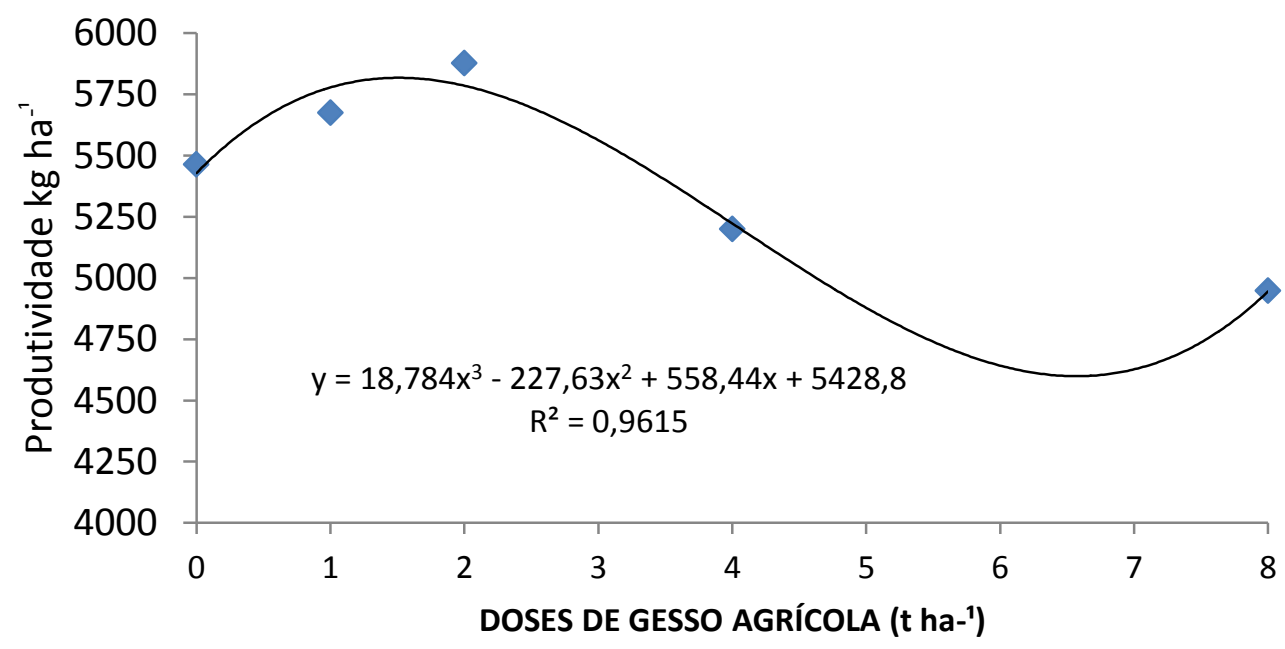

\section{DISCUSSÃO}

A calagem e a gessagem superficial apresentou resultados conclusivos em relação à produtividade do milho, quando analisado o gesso agrícola separadamente e a interação do calcário com o gesso, o calcário analisado isoladamente não se obteve resultados significativos na produtividade, em solos ácidos manejados em plantio direto no sul do Brasil, trabalhos revelam 
respostas pouco expressivas do milho à aplicação superficial de calcário (PÖTTKER,. BEN, 1998; CAIRES et al., 1999; RHEINHEIMER et al., 2000).

E pelo pouco que se conhece de trabalhos feitos em sistemas plantio direto recémimplantados. A maioria dos trabalhos com aplicação de calcário e gesso em superfície foi realizada em condições de sistema plantio direto consolidado e em regiões sem limitação hídrica (CAIRES et al., 2005), o que pode ter interferido no efeito da calagem superficial na correção da acidez do subsolo (ALLEONI et al., 2005). Contudo, pouco se conhece sobre os efeitos, nos atributos químicos do solo, da aplicação de calcário e gesso em superfície num sistema plantio direto recém-implantado e em região com limitação hídrica durante alguns meses do ano (SORATTO et al. 2008).

As alterações no solo proporcionadas por aplicações de calcário e gesso são complexas e seus efeitos sobre as plantas são difíceis de ser isolados. (CAIRES et al., 2004)

Já quando se foi analisado isoladamente, a aplicação de gesso, verificou-se diferença estatísticas entre as dosagens resultados semelhantes foram encontrados na literatura. Respostas positivas do milho à aplicação de gesso têm sido observadas em variadas condições de solo e clima (CAIRES et al., 1999).

Isso pode ter ocorrido por diversos fatores, um deles pode ter sido a lixiviação do magnésio, nutriente que lixivia quando aplicado o gesso agrícola em doses altas causando um desbalanço em relação ao cálcio. A lixiviação de $\mathrm{Mg}$ trocável tem sido uma resposta frequente nos estudos com aplicação de gesso em solos (CAIRES et al., 1999). Assim, quando o gesso é aplicado em doses elevadas no solo, devem ser desenvolvidas estratégias para minimizar as perdas de $\mathrm{Mg}$ trocável. Por essa razão, o uso de gesso não tem sido recomendado de forma isolada, mas, sim, em combinação com o calcário dolomítico. (CAIRES et al., 2004)

Os dados com uma dose de calcário comparado com as demais doses de gesso agrícola, onde observa que conforme as doses de gesso agrícola aumentam, a produtividade de grãos diminui ,sendo assim, um efeito negativo do excesso de gesso agrícola aplicado no solo.

\section{CONCLUSÃO}

Conclui-se que a aplicação de calcário e gesso agrícola interferiu de forma significativa na produtividade do milho, o gesso agrícola aplicado em altas doses ( $4 \mathrm{t} \mathrm{ha}^{-1}$ e $8 \mathrm{t} \mathrm{ha}^{-1}$ ) de forma isolada promove queda da produtividade, as doses de $2 \mathrm{t} \mathrm{ha}{ }^{-1}$ de calcário e gesso agrícola, foi a que se obteve melhor resposta na produtividade do milho, ressaltando que deve se estudar por mais anos a reação que ambos terão no solo e nas próximas culturas.

\section{REFERÊNCIAS}

ALBUQUERQUE, L. SANGOI; M. ENDER. Efeitos da integração lavoura-pecuária nas propriedades físicas do solo e características da cultura do milho. R. Bras. Ci. Solo, 25:717-723, 2001 https://doi.org/10.1590/S0100-06832001000300021

ALLEONI, L.R.F.; CAMBRI, M.A.; CAIRES, E.F. Atributos químicos de um Latossolo de cerrado sob plantio direto, de acordo com doses e formas de aplicação de calcário. R. Bras. Ci. Solo, 29:923934, 2005 https://doi.org/10.1590/S0100-06832005000600010

BALL-COELHO, B.R.; ROY, R.C.; SWANTON, C.J. Tillage alters corn root distribution in coarsetextured soil. SoilTill. Res., 45:237-249, 1998. 
BARROS, J.F. C, A Cultura do Milho (2014). Disponível em: https://www.passeidireto.com/arquivo/6001152/a-cultura-do-milho acessado em 30/10/2016).

BRAGA, F.A.; VALE F.R.; MUNIZ, J.A. Movimentação de nutrientes no solo, crescimento e nutrição mineral do eucalipto, em função de doses de gesso e níveis de irrigação. Revista Brasileira de Ciência do Solo, v.19, p.69-77, 1995.

CAIRES, W. A.; CHUEIRI, E. F.; MADRUGA; A. FIGUEIREDO. Alterações de características químicas do solo e resposta da soja ao calcário e gesso aplicados na superfície em sistema de cultivo sem preparo do solo. R. Bras. Ci. Solo, 22:27-34, 1998. https://doi.org/10.1590/S0100$\underline{06831998000100004}$

CAIRES, E. F.; et al. Produção de milho, trigo e soja em função das alterações das características químicas do solo pela aplicação de calcário e gesso na superfície, em sistema de plantio direto.

Revista Brasileira de Ciência do Solo, Viçosa, v.23, p.315-327, 1999. https://doi.org/10.1590/S0100-06831999000200016

CAIRES, E.F.; et al. Correção da acidez do solo, crescimento radicular e nutrição do milho de acordo com a calagem na superfície em sistema plantio direto. R. Bras. Ci. Solo, 26:1011-1022, 2002. https://doi.org/10.1590/S0100-06832002000400019

CAIRES E.F.; et al Alterações químicas do solo e resposta do milho à calagem e aplicação de gesso. R. Bras. Ci. Solo, 28:125-136, 2004. https://doi.org/10.1590/S0100-06832004000100013

CAIRES, E.F.; et al. G. Surface application of lime for crop grain production under a no-till system.Agron. J., 97:791-798, 2005. https://doi.org/10.2134/agronj2004.0207

CANTARELLA, H. Calagem e adubação do milho. In: BÜLL, L.T. ; CANTARELLA, H., eds. Cultura do milho: fatores que afetam a produtividade. Piracicaba, POTAFOS, 1993. p.147-196.

CHIODEROLII, C.A; et al. Consorciação de braquiárias com milho outonal em plantio direto sob pivô central,Eng. Agríc. vol.30 no. 6 Jaboticabal Dec. 2010.

COLEMAN, N.T.; et al F., eds. Soil acidity and liming. Madison, American Society of Agronomy, 1967. P.1-41. 